\title{
ВОЗДЕЙСТВИЕ ФАКТОРОВ ОКРУЖАЮЩЕЙ СРЕДЫ, ПРОФЕССИОНАЛЬНОЙ ДЕЯТЕЛЬНОСТИ И ПИЩЕВЫХ ДОБАВОК НА МАТЬ ВО ВРЕМЯ БЕРЕМЕННОСТИ И РИСК ВОЗНИКНОВЕНИЯ НЕСИНДРОМАЛЬНЫХ ОРОФАЦИАЛЬНЫХ РАСЩЕЛИН ПЛОДА (ОБЗОР ЛИТЕРАТУРЫ)
}

\section{THE IMPACT OF ENVIRONMENTAL FACTORS, OCCUPATIONAL ACTIVITIES, AND DIETARY SUPPLEMENTS ON THE MOTHER DURING PREGNANCY AND THE RISK OF NON-SYNDROMIC OROFACIAL CLEFT FORMATION IN THE FETUS (LITERATURE REVIEW)}

A. Yakimova

N. Datsenko

I. Marinkin

Summary. The article is devoted to the study of the effects of environmental factors, occupational activities and dietary supplements on the mother during pregnancy and the risk of nonsindromal orophacial fetal rushes. The authors reviewed the available epidemiological data on the risk of often occurring congenital anomalies related to environmental exposure, individual and socioeconomic risk factors, as well as their reduction under the conditions of multivitamin and folic acid use. It is suggested that the development of epigenetic biomarkers for orophacial cleft prediction and the use of epigenetic mechanisms to prevent disease are promising.

Keywords: fetal malformations, occupational hazards, orofacial cleft, folic acid, neonatal morbidity.

\author{
Якимова Анна Валентиновна \\ Д.м.н., профессор, Новосибирский государственный \\ медицинский университет \\ yakimova2@ngmu.ru \\ Даценко Наталья Сергеевна \\ Ассистент, Новосибирский государственный \\ медицинский университет \\ datsenko.natasha@yandex.ru \\ Маринкин Игорь Олегович \\ Д.м.н., профессор, Новосибирский государственный \\ медицинский университет \\ rector@ngmu.ru
}

Аннотация. Статья посвящена исследованию воздействия факторов окружающей среды, профессиональной деятельности и пищевых добавок на мать во время беременности и риск возникновения несиндромальных орофациальных ращелин плода. Авторами проведен обзор имеющихся эпидемиологических данных о риске часто встречающихся врожденных аномалий, связанных с воздействием окружающей среды, с индивидуальными и социально-экономическими факторами риска, а также их снижения в условиях применения поливитаминов и фолиевой кислоты. Высказывается тезис о том, что перспективными являются разработки эпигенетических биомаркеров для прогнозирования орофациальных расщелин и использования эпигенетических механизмов для предотвращения заболевания.

Ключевые слова: пороки развития плода, профессиональные вредности, орофациальные расщелины, фолиевая кислота, заболеваемость новорожденных.

Врожденные пороки развития челюстно-лицевой области - расщелины губы и нёба считаются одними из самых распространенных аномалий развития. В мире сохраняется высокий уровень частоты рождения детей с врожденной расщелиной губы и нёба частота составляет от 1 на 300 живорожденных до 1 на 1000. Рецидивы расщелины у членов пострадавших семей в 40 раз выше, чем у населения в целом. [12]. Всемирная организация здравоохранения определяет решение проблемы инвалидности при врожденной расщелине губы и нёба как стратегическую задачу [1]. 
В этой работе представлен обзор имеющихся эпидемиологических данных о риске часто встречающихся врожденных аномалий, связанных с воздействием окружающей среды, а также с индивидуальными и социально-экономическими факторами риска. В последние годы подчеркивается важность окружающей среды, как основного фактора репродуктивного риска. Человек может подвергаться воздействию загрязняющих веществ, присутствующих на рабочем месте, а население может подвергаться воздействию множества источников загрязнения окружающей среды, таких как вода, почва и воздух. Беременные женщины и развивающийся плод особенно чувствительны к воздействию окружающей среды [3]. Поиск литературы проводился в PubMed для оценки доказательств путем отбора статей, опубликованных с 1996 по 2021 год и посвященных исследованиям на людях. Для этого обзора были выбраны описательные и аналитические эпидемиологические исследования (когортные, случай-контроль, перекрестные и экологические), систематические обзоры и метанализы, сообщающие об оценках связи между исходом в виде возникновения орофациальных расщелин плода и, по крайней мере, одним из факторов риска.

Несиндромальные расщелины полости рта относятся к числу наиболее распространенных врожденных аномалий. На основании эпидемиологических и эмбриологических данных расщелина губы и / или неба и расщелина неба считаются отдельными формами орофациальной расщелины. Значительные ассоциации были замечены для воздействия на мать органических растворителей, тяжелых металлов или пестицидов и всех подтипов. Результаты многопараметрического анализа показали, что воздействие на мать органических растворителей, тяжелых металлов или пестицидов и любое использование поливитаминов матерью в течение периода до зачатия были связаны с риском ОФР [8]. Несколько исследований сообщают о повышенном риске возникновения расщелин в полости рта, связанных с профессиональным воздействием органических растворителей на мать, Laumon B, и соавторы [15] сравнили воздействие любого органического растворителя на мать: в опытную группу включены 200 младенцев с заячьей губой и / или волчьей пастью и в контрольную - 400 младенцев, и расчетное отношение шансов составило 1,62 (95\% ДИ 1. 04-2.52). Затем сравнили воздействие девяти подгрупп растворителей. Только соотношение, связанное с галогенированными алифатическими растворителями $(4,40,95 \%$ ДИ 1,41-16,15), значительно отличалось от единицы. Контроль возможных искажающих факторов - пола ребенка, семейного анамнеза, материнской эпилепсии - не изменил эту оценку отношения шансов. Lorente C, и соавторы [17] изучали воздействия профессиональных вредно- стей на 851 женщину (100 из них родили детей с ОФР и 751 - здоровых детей), все женщины работали в течение 1 триместра беременности. Отношения шансов были оценены с помощью многомерного анализа, включая род занятий матери, профессиональные вредности, возраст, социально-экономический статус. Только расщелина нёба была значимо связана с деятельностью матери в такой сфере, как парикмахерское дело (ОШ 5,1, 95\% ДИ 1,0-26,0). Большинство работающих матерей имели административную и техническую работу. Только $14 \%$ работали в сфере услуг, а 6\% - в производстве. Коэффициенты шансов были оценены для каждого типа расщелины и были самыми высокими для рабочих профессий. В этой группе коэффициенты шансов были выше для расщелины нёба, и статистически значимы для расщелины нёба только для 2 профессий: домработницы (ОШ 2,80, 95\% ДИ 1,08-7,24) и парикмахеры (ОШ5,10 95\% ДИ 1,01-25,9). Для производственных работников повышенные коэффициенты шансов в первую очередь касались также расщелины неба. Анализ показывает, что следующие профессиональные вредности связаны с ОФР: алифатические альдегиды (OR2.1, 95\% ДИ 0,8-5,9), простые эфиры гликоля (OR1.7, 95\% ДИ 0,9-3,3), соединения свинца (OR4.0, 95\% дИ 1,3-12,2), трихлорэтилен (OR6.7, 95\% ДИ 0,9-49,7). Важным преимуществом этого исследования было то, что оценка воздействия проводилась экспертами по промышленной гигиене. Это помогло уменьшить возможную предвзятость отзыва и стандартизировать оценки. Ограниченное количество пациентов не позволяет нам сделать однозначные выводы относительно безопасности профессиональной деятельности в первом триместре беременности. Влияние поливитаминов. В январе 2011 года Министерство окружающей среды Японии начало крупномасштабный проект эпидемиологического исследования под названием «Японское исследование окружающей среды и детей» (JECS). Это- общенациональное перспективное когортное исследование, целью которого является набор примерно 100000 беременных женщин и их детей; период набора начался в январе 2011 года и продлился до марта 2014 года. В результате, JECS охватил около 3\% новорожденных в Японии в 2013 году. Питание матери оценивали с помощью полуколичественного опросника частоты приема пищи в первом триместре. Анкета включала в себя список продуктов, обычно потребляемых в Японии, а также информацию о стандартных размерах порций [22]. Потребление лекарств и добавок исследовалось в течение трех периодов: до подтверждения беременности, с начала беременности до 12 недели (первый триместр) и после 12 недели. После исключения детей, матери которых не сообщили данных о питании, в анализ были включены 98787 (94,9\%) пар мать-ребенок. Межгрупповые сравнения для возникновения орофациальных расщелин (ОФР) были проведены с исполь- 
зованием тестов Крускала-Уоллиса или х ². Впоследствии потребление поливитаминов и результаты были проанализированы в основном анализе. Результаты этого анализа продемонстрировали связь между приемом поливитаминных добавок во время беременности и увеличением частоты возникновения орофациальных пороков. В частности, по сравнению с отсутствием приема добавок, прием до подтверждения беременности или прием в течение первого триместра беременности был связан с двукратным увеличением относительного риска орофациальных расщелин у потомства. Примечательно, что эта связь наблюдалась в течение первого триместра беременности, но не была значимой в дальнейшем [23]. У этого исследования было несколько ограничений. Во-первых, данные о потреблении матерью поливитаминных добавок и других лекарств были основаны на интервью, что могло привести к неправильной классификации воздействия из-за предвзятости самооценки. Кроме того, не были уточнены типы используемых поливитаминных добавок, поэтому их компоненты и дозы были неизвестны. Эти ограничения предполагают, что в дальнейших исследованиях следует рассмотреть компоненты поливитаминных добавок и их влияние на частоту возникновения орофациальных ращелин. В этом направлении представляют интерес работы, посвященные влиянию фолиевой кислоты на развитие плода.

\section{Фолиевая кислота}

С использованием результатов 6 когортных исследований и 31 исследования методом случай-контроль, был проведен мета-анализ, целью которого было оценить, может ли прием фолиевой кислоты во время беременности снизить риск орофациальных расщелин. Результаты основного анализа показали, что добавление фолиевой кислоты к рациону матери было связано со скромным, но статистически значимым снижением риска всех подтипов расщелины $(\mathrm{OR}=0,69,95 \%$ ДИ: 0,60, 0,78) [11]. Более скромное по масштабам исследование (случай-контроль) на ту же тему (и аналогичными результатами) было ранее проведено в Норвегии: было показано, что добавление фолиевой кислоты на ранних сроках беременности (> или $=400$ мкг / день) было связано со снижением риска ОФР, после поправки на поливитамины, курение и другие потенциальные мешающие факторы (скорректированное отношение шансов 0,61, 95\% доверительный интервал от 0,39 до 0,96) [21]. В исследовании случай-контроль для определения связи между несиндромными расщелинами и фолиевой кислотой Литтл и др. пришли к выводу, что более высокое потребление фолиевой кислоты, по-видимому, не предотвращает расщелины [5], в то время как исследование, проведенное в Нидерландах, продемонстрировало, что добавка фолиевой кислоты в пе- риконцептивный период матери была полезна для уменьшения риска расщелины губы [18].

Кокрановский обзор фолиевой кислоты в периконцепции при обычной дозировке [4] и систематический обзор и метаанализ, проведенный Джонсоном и Литтлом [13] не показал никаких доказательств профилактических эффектов в отношении орофациальных расщелин, а метаанализ, проведенный Джаханбином и соавторами [10], напротив, показал, что периконцептивные поливитамины, содержащие фолиевую кислоту, оказывают защитное действие на расщелины полости рта. Требуются многоцентровые рандомизированные контролируемые испытания на разных континентах с большим количеством случаев и контроля, оценивающие эффективность именно фолиевой кислоты, а не поливитаминов, содержащих фолиевую кислоту, в предотвращении возникновения и рецидива орофациальной расщелины.

\section{Эпигенетика \\ и орофациальные рашелины}

В то время как генетические влияния на наши черты включают вариации в последовательности нашей ДНК, эпигенетические влияния включают изменения в том, как ДНК упаковывается, экспрессируется и как кодирует синтез белка. В целом, ДНК остается той же, но химические модификации изменяют уровни активности генов. При метилировании ДНК, которое является наиболее часто изучаемым эпигенетическим механизмом, метильные группы присоединяются к ДНК и могут влиять на экспрессию генов, часто отключая их. Хотя каждая клетка в каждой ткани имеет одинаковую последовательность ДНК, эпигенетические процессы в разных клетках различаются. Это означает, что факторы окружающей среды могут вызывать долгосрочные изменения в активности генов, которые, в свою очередь, могут влиять на здоровье и болезни на протяжении всей жизни человека [6]. Эпигенетические изменения, в частности метилирование ДНК, могут опосредовать как генетические факторы, так и факторы окружающей среды и могут способствовать пониманию молекулярного патогенеза орофациальных расщелин. Хотя большая часть ДНК лишена метилирования на раннем этапе развития, эксперименты показали, что метки могут оставаться на определенных частях ДНК, которые вызывают восстановление паттернов аберрантного метилирования во время развития [7]. Эпигенетические процессы, особенно метилирование ДНК, важны для определения структуры и функции развивающихся эмбриональных тканей, поэтому вполне вероятно, что аберрантные эпигенетические механизмы могут вносить вклад в ОФР. Благодаря своей роли кофермента одноуглеродного метаболизма фоллат непосредственно участвует в переносе метильных групп при 
метилировании ДНК, что может служить подтверждением фактов дефицита фолиевой кислоты и нарушения метаболизма фолиевой кислоты как факторов риска для ОФР. Недавний метаанализ исследований ассоциаций на уровне всего эпигенома в 13 когортах $(n=6685)$ выявил более 6000 сайтов около 3620 генов, которые были дифференциально метилированы по отношению к материнскому курению [14]. Двадцать семь из этих генов ранее были связаны с ОФР, включая $V A X 1, N O G, B M P 4$ и $M S X 1$. Это говорит о том, что курение матери может влиять на риск развития ОФР у потомства через механизм, включающий метилирование ДНК. Howe et al. [9]. сообщили о 21 предполагаемом сайте CpG, где метилирование может опосредовать генетические аллельные эффекты на предрасположенность к несиндромальной расщелине губы / неба. Какое же клиническое значение может иметь выявление эпигенетического механизма возникновения ОФР? Появляются два возможных клинических применения: (1) разработка эпигенетических биомаркеров для прогнозирования или классификации заболевания и (2) использование эпигенетических механизмов для предотвращения или лечения заболевания [20] при этом первая возможность представляется более реальной.

\section{Пассивное курение, как фактор окружаюшей среды}

Одиннадцать из 14 исследований, включенных в метаанализ [19], представили данные об активном курении матерей, а также о последствиях пассивного курения у некурящих матерей. В совокупности пассивное курение увеличивало риск несиндромальных орофацильных расщелин (OR: 2,07, 95\% ДИ: 1,42-3,01) даже больше, чем активное курение (OR: 1,5, 95\% ДИ: 1,17-1,93), хотя это различие не было статистически значимым $(P=0,17)$, и между исследованиями наблюдалась значительная неоднородность. Учитывая, что активные курильщики подвергаются как прямому вдыханию, так и пассивному курению, более сильная ассоциация с пассивным курением, чем с активным курением, является неожиданной. Интересные данные метаанализа и систематического обзора представили Little J и соавторы [16]. Это исследование подтверждает гипотезу о том, что курение матери повышает риск развития орофациальных расщелин. Эффект был более сильным и последовательным для расщелины губы, чем для нёба. Получены статистически значимые ассоциации между курением матери и заячьей губой, с волчьей пастью или без нее (относительный риск 1,34, 95\% доверительный интервал $1,25-1,44)$ и между курением матери и волчьей пастью (относительный риск 1,22, 95\% доверительный интервал 1,10-1,35). Демонстрация связи между курением табака во время беременности и ОФР может создать основу для нового подхода к сокращению курения.

\section{Зак^ючение}

Проведенный анализ литературных данных за 25 лет позволяет сделать вывод о некотором повышении риска несиндромальных ОФР у женщин, работающих парикмахерами и домработницами, а также - занятых на производстве с использованием некоторых химических веществ, в первом триместре беременности. Также курение беременных, в том числе, пассивное, является фактором риска такого порока развития плода. Представляются заманчивыми перспективы разработки эпигенетических биомаркеров для прогнозирования орофациальных расщелин и использования эпигенетических механизмов для предотвращения заболевания.

\section{ЛИТЕРАТУРА}

1. Касимовская Н.А., Шатова Е.А. Врожденная расщелина губы и нёба у детей: распространенность в России и в мире, группы факторов риска // Вопросы современной педиатрии. 2020. № 19(2). С. 142-145.

2. Baldacci S, Gorini F, Santoro M, Pierini A, Minichilli F, Bianchi F. Environmental and individual exposure and the risk of congenital anomalies: a review of recent epidemiological evidence. Epidemiol Prev. 2018 May-Aug;42(3-4 Suppl 1):1-34.

3. Baldacci S, Gorini F, Santoro M, Pierini A, Minichilli F, Bianchi F. Environmental and individual exposure and the risk of congenital anomalies: a review of recent epidemiological evidence. Epidemiol Prev. 2018 May-Aug;42(3-4 Suppl 1):1-34.

4. De-Regil L M, Peña-Rosas J P, Fernández-Gaxiola A C, Rayco-Solon P. Effects and safety of periconceptional oral folate supplementation for preventing birth defects. Cochrane Database Syst.Rev. 2015;2015(12): (D007950).

5. Folate and clefts of the lip and palate — a U.K.-based case-control study: Part I: Dietary and supplemental folate.Little J, Gilmour M, Mossey PA, Fitzpatrick D, Cardy A, Clayton-Smith J, Fryer AE, ITS MAGIC collaboration.Cleft Palate Craniofac J. 2008 Jul; 45(4):420-7).

6. Godfrey, K.M., Sheppard, A., Gluckman, P.D., Lillycrop, K.A., Burdge, G.C., McLean, C., Rodford, J., Slater-Jefferies, J.L., Garratt, E., Crozier, S.E. Epigenetic gene promoter methylation at birth is associated with child's later adiposity. Diabetes. 2011; 60: 1528-1534.

7. Greer, E.L., Bees-Sims, S.E., Brookes, E., Spadafora, R., Zhu, Y., Rothbart, S.B., Aristizabal-Corrales, D., Chen, S., Badeaux, A., Jin, Q.A histone methylation network regulates transgenerational epigenetic memory in C.elegans. Cell Rep. 2014; 10: 113-126.

8. Hao Y, Tian S, Jiao X, et al. Association of Parental Environmental Exposures and Supplementation Intake with Risk of Nonsyndromic Orofacial Clefts: A CaseControl Study in Heilongjiang Province, China. Nutrients. 2015;7(9):7172-7184. Published 2015 Aug 27. 
9. Howe LJ, Richardson TG, Arathimos R, Alvizi L, Passos-Bueno MR, Stanier P, Nohr E, Ludwig KU, Mangold E, Knapp M, et al. Evidence for DNA methylation mediating genetic liability to non-syndromic cleft lip/palate. Epigenomics. 2019;11:133-45.

10. Jahanbin A, Shadkam E, Miri H H, Shirazi A S, Abtahi M. Maternal folic acid supplementation and the risk of oral clefts in offspring. J (raniofac Surg. 2018;29(06): e534-e541.

11. Jahanbin A, Shadkam E, Miri HH, Shirazi AS, Abtahi M. Maternal Folic Acid Supplementation and the Risk of Oral Clefts in Offspring. J Craniofac Surg. 2018 Sep;29(6): e534-e541.

12. Jayarajan R, Natarajan A, Nagamuttu R. Efficacy of Periconceptional High-Dose Folic Acid in Isolated Orofacial Cleft Prevention: A Systematic Review. Indian J Plast Surg. 2019;52(2):153-159.

13. Johnson C $Y$, Little J. Folate intake, markers of folate status and oral clefts: is the evidence converging? Int J Epidemiol. 2008;37(05):1041-1058.

14. Joubert, B.R., Felix, J.F., Yousefi, P., Bakulski, K.M., Just, A.C., Breton, C., Reese, S.E., Markunas, C.A., Richmond, R.C., Xu, C-J DNA methylation in newborns and maternal smoking in pregnancy: genome-wide consortium meta-analysis. Am J Hum Genet. 2016b; 98: 680-696).

15. Laumon B, Martin J L, Collet P.et al Exposure to organic solvents during pregnancy and oral clefts: a case-control study. Reprod Toxicol 1996.-1015-1019.

16. Little J, Cardy A, Munger RG. Tobacco smoking and oral clefts: a meta-analysis. Bull World Health Organ. 2004 Mar;82(3):213-8.

17. Lorente C, Cordier S, Bergeret A.et al Maternal occupational risk factors for oral clefts. Occupational Exposure and Congenital Malformation Working Group. Scand J Work Environ Health 2000.-26.-137-145.

18. Periconceptional folate intake by supplement and food reduces the risk of nonsyndromic cleft lip with or without cleft palate.van Rooij IA, Ocké MC, Straatman H, Zielhuis GA, Merkus HM, Steegers-Theunissen RP Prev Med. 2004 0ct; 39(4):689-940).

19. Sabbagh HJ, Hassan MH, Innes NP, Elkodary HM, Little J, Mossey PA. Passive smoking in the etiology of non-syndromic orofacial clefts: a systematic review and meta-analysis. PLoS One. 2015;10(3): e0116963.

20. Sharp GC, Stergiakouli E, Sandy J, Relton C. Epigenetics and Orofacial Clefts: A Brief Introduction. The Cleft Palate-Craniofacial Journal. 2018;55(6):795-797.

21. Wilcox AJ, Lie RT, Solvoll K, Taylor J, McConnaughey DR, Abyholm F, Vindenes H, Vollset SE, Drevon CA. Folic acid supplements and risk of facial clefts: national population based case-control study. BMJ. 2007 Mar 3;334(7591):464.

22. Yokoyama $Y$, Takachi R, Ishihara J, et al. . Validity of short and long self-administered food frequency questionnaires in ranking dietary intake in middle-aged and elderly Japanese in the Japan public health Center-Based prospective study for the next generation (JPHC-NEXT) protocol area. J Epidemiol 2016;26:420-32.

23. Yoshida S, Takeuchi M, Kawakami C, Kawakami K, Ito S; Japan Environment and Children's Study Group. Maternal multivitamin intake and orofacial clefts in offspring: Japan Environment and Children's Study (JECS) cohort study. BMJ Open. 2020;10(3): e035817.

(с) Якимова Анна Валентиновна ( yakimova2@ngmu.ru ),

Даценко Наталья Сергеевна ( datsenko.natasha@yandex.ru ), Маринкин Игорь Олегович ( rector@ngmu.ru ).

Журнал «Современная наука: актуальные проблемы теории и практики» 